\title{
Correction: The influence of neurological examination timing within hours after acute traumatic spinal cord injuries: an observational study
}

\author{
Nathan Evaniew - Babak Sharifi - Zeina Waheed • Nader Fallah (D) Tamir Ailon (D) Nicolas Dea - Scott Paquette • \\ Raphaele Charest-Morin • John Street • Charles G. Fisher • Marcel F. Dvorak • Vanessa K. Noonan • Carly S. Rivers • \\ Brian K. Kwon
}

Published online: 9 January 2020

(c) International Spinal Cord Society 2020

\section{Correction to: Spinal Cord \\ https://doi.org/10.1038/s41393-019-0359-0 \\ published online 08 October 2019}

In the original version of this article, Table 2 contained a number of erroneous values in the row " $>24-48 \mathrm{~h}$ $(n=10)$ ". The values " $22,26 \%$ ", "15, 18\%", and "7, 8\%" have now been corrected to " $4,40 \% "$, " $0,0 \%$ ", and " 1 , $10 \%$ ", respectively. Additionally, in the results section, the authors mistakenly stated that ". $.50 \%$ of patients examined at $4 \mathrm{~h}$ or less converted by at least two grades in comparison with $15 \%$ of patients examined at more than $4 \mathrm{~h}(\mathbf{R R}=\mathbf{3 . 3}$, $\boldsymbol{p}=\mathbf{0 . 0 3})$ ". This sentence has now been corrected to: “...50\% of patients examined at $4 \mathrm{~h}$ or less converted by at least two grades in comparison with $\mathbf{2 1 \%}$ of patients examined at more than $4 \mathrm{~h}(\mathbf{R R}=\mathbf{2 . 4}, \boldsymbol{p}=\mathbf{0 . 0 4})$ ". This has been corrected in both the PDF and HTML versions of the article. 